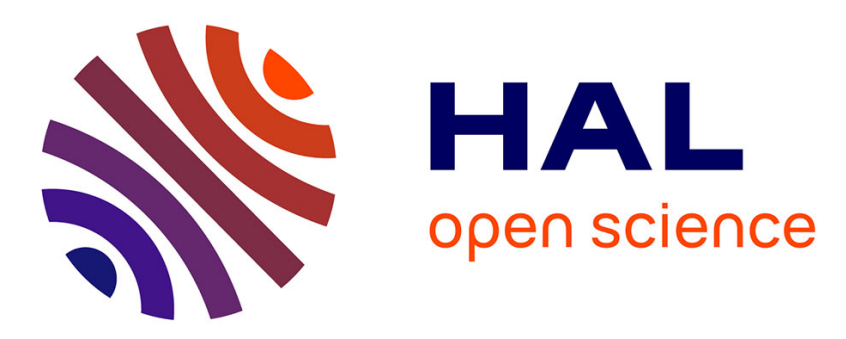

\title{
Integrated multi-criteria velocity and semi-active suspension control based on look-ahead road information
}

Hakan Basargan, András Mihály, Péter Gáspár, Olivier Sename

\section{To cite this version:}

Hakan Basargan, András Mihály, Péter Gáspár, Olivier Sename. Integrated multi-criteria velocity and semi-active suspension control based on look-ahead road information. MED 2020 28th Mediterranean Conference on Control and Automation, Sep 2020, Saint-Raphaël, France. 10.1109/MED48518.2020.9182953 . hal-02940727

\section{HAL Id: hal-02940727 \\ https://hal.univ-grenoble-alpes.fr/hal-02940727}

Submitted on 16 Sep 2020

HAL is a multi-disciplinary open access archive for the deposit and dissemination of scientific research documents, whether they are published or not. The documents may come from teaching and research institutions in France or abroad, or from public or private research centers.
L'archive ouverte pluridisciplinaire $\mathbf{H A L}$, est destinée au dépôt et à la diffusion de documents scientifiques de niveau recherche, publiés ou non, émanant des établissements d'enseignement et de recherche français ou étrangers, des laboratoires publics ou privés. 


\title{
Integrated multi-criteria velocity and semi-active suspension control based on look-ahead road information
}

\author{
Hakan Basargan, András Mihály, Péter Gáspár and Olivier Sename
}

\begin{abstract}
Semi-active suspension control and vehicle cruise control systems have already been developed by researchers and adapted by automotive companies. Most of these systems react on actual road irregularities and terrain characteristics, and the control for each subsystem is designed separately. However, since oncoming road conditions can be known by using historic road information and GPS navigation system, the paper introduces a method to build in look-ahead road data in the control of the adaptive semi-active suspension, moreover, design the vehicle velocity for the cruise controller considering comfort and energy efficiency at the same time. The operation of the presented integrated suspension and velocity control system is validated by a real data simulation in TruckSim environment.
\end{abstract}

\section{INTRODUCTION}

Recently, vehicle technologies have been majorly studied in both academic and industry while vehicle suspension systems are an important research topic with significant developments in the last decades. Vehicle suspension systems can be classified in three categories, which are passive, semiactive, and active depending on the operation mode. The goal of the semi-active and active suspension is to improve vehicle safety and ride comfort, through minimizing the effects off road disturbances. Passive suspension is still commonly used, but it is limited in improving ride comfort or suspension deflection [1]. Semi-active suspension systems apply variable damping characteristics expressing a significant improvement over passive suspension systems. Semi-active suspension systems can be adjusted to provide better suspension by absorbing energy, while they cannot forward energy to the system as an active suspension.

There are numerous publications related to design of semi-active suspension control ([2],[3],[4],[5]) which are safety-oriented problems ([6], [7]) and comfort-oriented problems([8], [9]), while most of them don't consider velocity design and several road distortions. This study proposes

H. Basargan is with Department of Control for Transportation and Vehicle Systems, Budapest University of Technology and Economics, Stoczek u. 2, H-1111 Budapest, Hungary. E-mail: hakanbasargandedu. bme. hu

A. Mihály and P. Gáspár are with Systems and Control Laboratory, Institute for Computer Science and Control, Kende u. 13-17, H-1111, Budapest, Hungary. E-mail: [andras.mihaly; peter.gaspar] @sztaki.hu

O. Sename is with GIPSA-lab, INPG, Université Grenoble Alpes, 11 Rue des Mathématiques, 38402 Grenoble, France. E-mail : E-mail: olivier.sename@gipsa-lab.grenoble-inp. fr

The research was supported by the National Research, Development and Innovation Office through the project 'Integration of velocity and suspension control to enhance automated driving comfort in road vehicles' (NKFIH 2018-2.1.13-TÉT-FR) a method to build in look-ahead road data in the control of the adaptive semi-active suspension, and besides, design the vehicle velocity for the cruise controller considering comfort and energy efficiency at the same time. The operation of the introduced integrated velocity and suspension control system is validated by a real data simulation in TruckSim environment.

The paper is organized as follows: Section II mentions energy efficient cruise control. Section III presents the control-oriented quarter-car model and the LPV controller synthesis. Section IV describes integration of the system and the method of defining the scheduling variable $\rho$ based on the look-ahead estimation algorithm. Section V demonstrates the operation of the proposed method in high-fidelity TruckSim simulation environment with real road data. Finally, concluding remarks are presented in Section VI.

\section{ENERGY EFFICIENT CRUISE CONTROL}

The look-ahead control algorithm has already been introduced in [10], hence here only a brief explanation is given. First, the selected look-ahead distance $L$ is split into $n$ number of road sections, see Fig. 1.

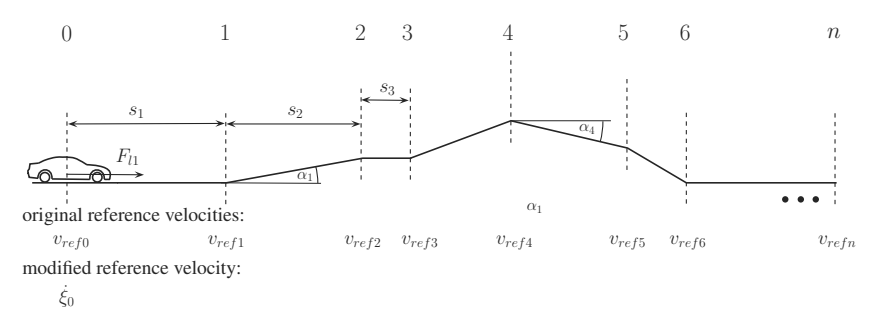

Fig. 1. Segmentation of forward road

Assuming slope angles and speed limits to be known for every road section endpoints, the following formula is given to calculate the optimal velocity:

$$
\lambda=\sqrt{\vartheta-2 s_{1}(1-Q)\left(\ddot{\xi}_{0}+g \sin \alpha\right)} .
$$

where

$$
\vartheta=Q v_{r e f, 0}^{2}+\sum_{i=1}^{n} \gamma_{i} v_{r e f, i}^{2}+\frac{2}{m} \sum_{i=1}^{n}\left(s_{i} F_{d i, r} \sum_{j=i}^{n} \gamma_{j}\right) .
$$


where $s_{i} i \in[1, n]$ is the road segment length with $L=$ $\sum s_{i}, v_{r e f, i}$ stands for the reference speed at every section endpoint, while $F_{d i, r}=m g \sin \alpha_{i}$ is the road disturbance force at each section point originated from the slopes on the look-ahead distance.

In order to meet the desired goals, two optimization problem must be solved at the same time: both longitudinal control force and deviation from the speed limits must be minimized. The first criteria related to energy efficiency is realized by the minimization of longitudinal control force: $F_{l 1}^{2} \rightarrow$ min. Hence, a quadratic optimization problem is solved given as:

$$
\bar{F}_{l 1}^{2}=\left(\beta_{0}(\bar{Q})+\beta_{1}(\bar{Q}) \bar{\gamma}_{1}+\ldots+\beta_{n}(\bar{Q}) \bar{\gamma}_{n}\right)^{2} \rightarrow \min
$$

Next, deviations from the speed limits must also be minimized, which is formulated as follows:

$$
\left|v_{\text {ref }, 0}-\dot{\xi}_{0}\right| \rightarrow \min
$$

Note, that optimal solution for this latter criterion is to choose $\breve{Q}=1$ and $\breve{\gamma}_{i}=0, i \in[1, n]$.

The convenient balance between the conflicting performances is set by introducing two further performance weight $0 \leq R_{1} \leq 1$ and $0 \leq R_{2} \leq 1$, with the constraint $R_{1}+R_{2}=1$. Here, performance weight $R_{1}$ is related to the relevance of energy optimal operation of the look-ahead cruise controller, while $R_{2}$ is connected to the importance of minimizing the total travel time.

\section{Modeling AND CONTROL SYNTHESIS OF THE SUSPENSION SYSTEM}

Several researchers already developed active semi-active suspension systems based on the quarter-car model with very different approaches. Although linear quadratic and $\mathcal{H}_{\infty}$ suspension control can guarantee good performance in both passenger comfort and stability, due to the fixed weighting of performances a dynamic control reconfiguration is not possible, see [11]. In [12] an approach using on-line road profile identification has been introduced, thus the semiactive suspension system had road adaptation capabilities. Here, the semi-active suspension control is founded on the Linear Parameter Varying (LPV) framework, as already introduced in see [13], [14].

The layout of the commonly used two-degree-of-freedom quarter-car model is shown in Figure 2. The dynamic model of the quarter-car semi-active suspension system and the actuator is written as follows:

$$
\begin{aligned}
& m_{s} \ddot{q}_{1}+b_{s}\left(\dot{q}_{1}-\dot{q}_{2}\right)+k_{s}\left(q_{1}-q_{2}\right)+F_{m r}=0 \\
& m_{u} \ddot{q}_{2}+b_{s}\left(\dot{q}_{2}-\dot{q}_{1}\right)+k_{s}\left(q_{2}-w\right)-F_{m r}=0
\end{aligned}
$$

where the actuator dynamics is approximated as

$$
\dot{F}_{m r}=-\frac{1}{\tau} F_{m r}+\frac{1}{\tau} u \text {. }
$$

Here, $m_{s}$ is the sprung mass of the quarter vehicle, $m_{u}$ represents the unsprung mass, $k_{t}$ is the stiffness of the tire, $k_{s}$ is the stiffness of the spring, $b_{s}$ is the damping rate of the shock absorber, while $F_{m r}$ is the control force generated by

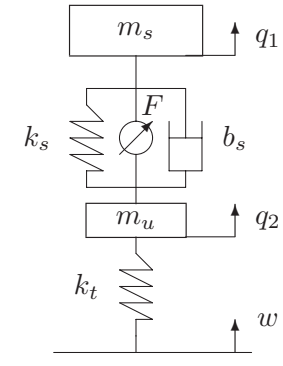

Fig. 2. Quarter-car model

the actuator and $u=F$ is the control input of the system. Note, that $q_{1}$ and $q_{2}$ are the vertical displacement of the sprung mass and the unsprung mass, while road disturbance is denoted with $w$. The nominal parameters of the quarter-car model for the front and rear suspension is shown in Table I.

TABLE I

SUSPENSION PARAMETERS

\begin{tabular}{|l|l|l|l|}
\hline $\begin{array}{l}\text { Parameters } \\
\text { (symbols) }\end{array}$ & $\begin{array}{l}\text { Front } \\
\text { suspension }\end{array}$ & $\begin{array}{l}\text { Rear } \\
\text { suspension }\end{array}$ & Unit \\
\hline \hline sprung mass $\left(m_{s}\right)$ & 214 & 336 & $\mathrm{~kg}$ \\
unsprung mass $\left(m_{u}\right)$ & 40 & 40 & $\mathrm{~kg}$ \\
suspension stiffness $\left(k_{s}\right)$ & 30 & 60 & $\mathrm{kN} / \mathrm{m}$ \\
tire stiffness $\left(k_{t}\right)$ & 220 & 220 & $\mathrm{kN} / \mathrm{m}$ \\
damping $\left(b_{s}\right)$ & 50 & 50 & $\mathrm{~N} / \mathrm{m} / \mathrm{s}$ \\
time constant $(\tau)$ & $1 / 30$ & $1 / 30$ & $\mathrm{~s}$ \\
\hline
\end{tabular}

The unmodelled dynamics $\Delta$ are also taken into consideration with $\left|\Delta\left(\omega_{1}\right)\right|=0.25$ at low frequencies and $\left|\Delta\left(\omega_{2}\right)\right|=1$ at high frequencies, and is assumed to be stable with the norm condition $\|\Delta\|_{\infty}<1$. The state vector $x$ is selected as $x=\left[\begin{array}{lllll}x_{1} & x_{2} & x_{3} & x_{4} & x_{5}\end{array}\right]^{T}$, in which the components are the vertical displacement of the sprung mass $x_{1}=q_{1}$, the vertical displacement of the unsprung mass $x_{2}=q_{2}$, their derivatives $x_{3}=\dot{q}_{1}, q_{4}=\dot{q}_{2}$ and the control force $x_{5}=F_{m r}$.

Next, performance specifications are defined in order to achieve a desired trade-off between ride comfort and road holding, while also taking control force into consideration. Hence, for the sake of increasing passenger comfort, the acceleration of the sprung mass must be minimized with the following optimization criterion: $z_{1}=\ddot{q}_{1} \rightarrow 0$. Directional stability is guaranteed with the minimization of suspension deflection, hence $z_{2}=\left(q_{1}-q_{2}\right) \rightarrow 0$. In order to reduce variations of side force to guarantee stability, the dynamic tire load must be minimized with the optimization criterion $z_{3}=\left(q_{2}-w\right) \rightarrow 0$. Finally, on order to avoid actuator saturation, the control force must also be considered with the optimization criterion $z_{4}=F \rightarrow 0$. These performances are put in a performance vector $z=\left[\begin{array}{llll}z_{1} & z_{2} & z_{3} & z_{4}\end{array}\right]^{T}$. The measured signal is the relative displacement between the masses, i.e $y=x_{1}-x_{2}$. The control input $u$ is the vertical force generated by the MR damper, with the dynamics listed in (6).

Next, the system given with (5) is transformed into state 
space representation form as follows:

$$
\begin{aligned}
\dot{x} & =A x+B_{1} w+B_{2} u \\
z & =C_{1} x+D_{11} w+D_{12} u \\
y & =C_{2} x+D_{21} w+D_{22} u
\end{aligned}
$$

The proposed high-level controller is founded on a weighting strategy formulated through a closed-loop architecture shown in Figure 3.

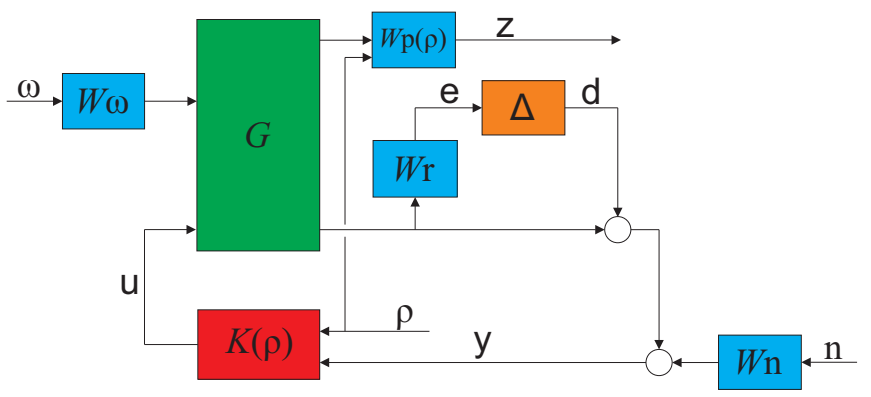

Fig. 3. Closed-loop interconnection structure

Here, $G$ is the quarter-car control oriented model defined in (7), $K$ is the designed Linear Parameter Varying (LPV) controller characterized with the scheduling variable $\rho$ responsible for control reconfiguration, $u$ is the control input, $y$ is the measured output, $n$ is the measurement noise, $z$ represents the performance outputs and $w$ stands for the road disturbance.

The uncertainties of the quarter-car model is considered with weighting function $W_{r}$ and $\Delta$. Note, that weighting functions should be considered as penalty functions, hence weights should be large where small signals are desired and vice versa. The aim of weighting function $W_{n}$ is to represent sensor noises, while weighting function $W_{w}$ stands for the road disturbances. The goal of weighting functions given in $W_{p}$ are to keep the sprung mass acceleration $\left(W_{p_{a}}\right)$, suspension deflection $\left(W_{p_{d}}\right)$, tire deflection $\left(W_{p_{t}}\right)$ and control input $\left(W_{p_{u}}\right)$ small over the required frequency range. Note, that while $W_{p_{a}}$ represents passenger comfort, $W_{p_{d}}$ and $W_{p_{t}}$ stands for directional stability and dynamic tire load. Since the predefined performance specifications may conflict with each other, weighting functions given in $W_{p}$ must be designed in a manner that an appropriate trade-off can be guaranteed between them. Moreover, in order to ensure control reconfiguration in case one of the predefined performances becomes more important due to estimated future road conditions, a scheduling variable $\rho$ $\in[0.01,0.99]$ is introduced to shape weighting function $W_{p_{a}}$, $W_{p_{d}}$ and $W_{p_{t}}$. Hence, these performance weighting functions related to passenger comfort and road holding are selected in a second-order proportional form as follows:

$$
\begin{aligned}
& W_{p_{a}}=\rho \frac{\alpha_{1} s+1}{T_{1} s+1} \\
& W_{p_{d}}=(1-\rho) \frac{\alpha_{2} s+1}{T_{2} s+1} \\
& W_{p_{t}}=(1-\rho) \frac{\alpha_{2} s+1}{T_{2} s+1},
\end{aligned}
$$

where $\alpha_{1,2,3}$ and $T_{1,2,3}$ are designed parameters. Note, that weighting functions $W_{p_{d}}, W_{p_{u}}, W_{r}, W_{n}$ and $W_{w}$ are all given in similar linear and proportional form without containing the scheduling variable $\rho$.

The LPV performance problem is to choose a parametervarying controller, which guarantees quadratic stability for the closed-loop system while the induced $\mathcal{L}_{2}$ norm from the disturbance $\omega$ to the performances $z$ is smaller than the value $\gamma$, as described in [15], [16]. Hence, the minimization task is given as:

$$
\inf _{K} \sup _{\varrho \in \mathcal{F}_{\mathcal{P}}} \sup _{\|w\|_{2} \neq 0, w \in \mathcal{L}_{2}} \frac{\|z\|_{2}}{\|w\|_{2}} \leq \gamma .
$$

The solution of an LPV problem is governed by the set of infinite dimensional LMIs being satisfied for all $\rho \in \mathcal{F}_{\mathcal{P}}$, thus it is a convex problem. In practice, this problem is set up by gridding the parameter space and solving the set of LMIs that hold on the subset of $\mathcal{F}_{\mathcal{P}}$, see [17].

The result of the presented design is a reconfigurable LPV controller, where $\rho=1$ stands for a setup where passenger comfort is preferred, whereas $\rho=0$ represents a controller focusing on stability and road holding of the vehicle. When $\rho$ is between these edge values, a combination of performances are guaranteed by the controller.

Since the modeled MR damper has limitations on the control input force $u=F$, a semi-optimal solution is given as follows:

$$
F=\left\{\begin{array}{c}
F_{\text {opt }}, \quad \text { if } \quad \dot{q}_{1}\left(\dot{q_{1}}-\dot{q_{2}}\right)>0 \\
0, \quad \text { if } \quad \dot{q}_{1}\left(\dot{q}_{1}-\dot{q}_{2}\right)<0
\end{array}\right.
$$

where $F_{o p t}$ is optimal force, $\dot{q}_{1}$ is sprung mass velocity and $\dot{q}_{1}-\dot{q}_{2}$ is deflection velocity.

\section{System InTEGRATION AND DECISION LOGIC MODEL}

The aim of this section is to describe system integration and the method of defining the scheduling variable $\rho$ based on the look-ahead estimation algorithm. Figure 4 shows the integration of the longitudinal and vertical control system, where a decision logic selects compatible $\rho$ based on the road data, previous measurements and the calculated optimal velocity $\lambda$ given by the look-ahead method using GPS based road data. Latter also serves as input for the cruise control that calculates the longitudinal control force for the vehicle.

It is necessary to categorize the road to select the right $\rho$ value according to different road types. The ISO 2631-1 standard characterize ride comfort based on the vibrations acting on the passengers [18]. Root mean square (RMS) of magnitudes of overall vibration is shown in Table II while the weighted RMS acceleration is expressed in terms of radians per second squared for rotational vibrations and defined in (11). ISO 2631-1 standard was considered to categorize the road with different distortion types, which can be seen in Table II.

$$
a_{w}^{R M S}=\sqrt{\frac{1}{T} \int_{0}^{T} a^{2}(t) d t}
$$




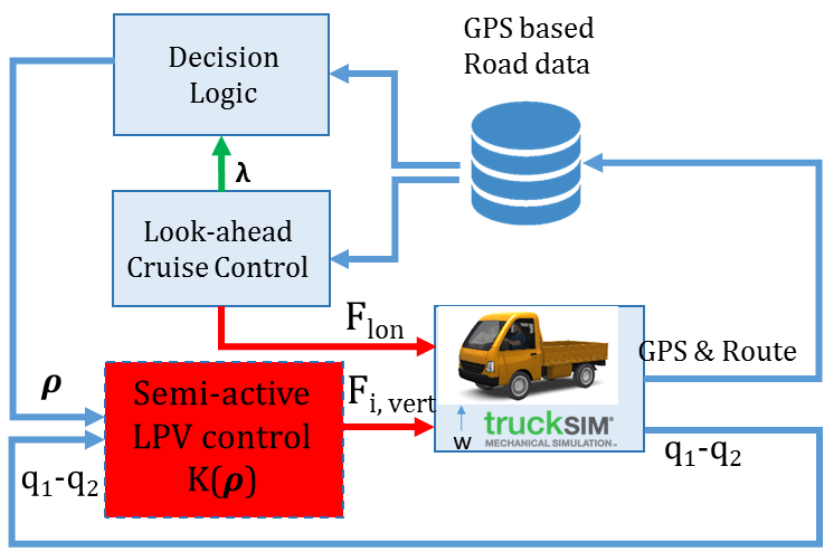

Fig. 4. Integration of the system

where $\mathrm{a}(\mathrm{t})$ is the frequency-weighted acceleration time and $\mathrm{T}$ is a number of acceleration values.

TABLE II

MAGNITUDES OF OVERALL VIBRATION ACCORDING TO ISO 2631-1:1997

\begin{tabular}{|l|l|}
\hline $\begin{array}{l}\text { Frequency-weighted vibration mag- } \\
\text { nitude (FWVM) }\end{array}$ & $\begin{array}{l}\text { Likely reaction in public } \\
\text { transport }\end{array}$ \\
\hline \hline Less than $0.315 \mathrm{~m} / \mathrm{s}^{2}$ & Not uncomfortable \\
\hline $0.315-0.63 \mathrm{~m} / \mathrm{s}^{2}$ & A little uncomfortable \\
\hline $0.5-1 \mathrm{~m} / \mathrm{s}^{2}$ & Fairly uncomfortable \\
\hline $0.8-1.6 \mathrm{~m} / \mathrm{s}^{2}$ & Uncomfortable \\
\hline $1.25-2.5 \mathrm{~m} / \mathrm{s}^{2}$ & Very uncomfortable \\
\hline Greater than $2 \mathrm{~m} / \mathrm{s}^{2}$ & Extremely uncomfortable \\
\hline
\end{tabular}

TABLE III

ROAD TYPE, VIBRATION MAGNITUDE VALUE AND SELECTED $\rho$

\begin{tabular}{|l|l|l|l|}
\hline Road Type & FWVM $\left(\mathrm{m} / \mathrm{s}^{2}\right)$ & Road Category & $\rho$ \\
\hline \hline Flat road & 0.0043 & Not uncomfortable & 1 \\
\hline Road with roughness & 0.026 & Not uncomfortable & 0 \\
\hline $10 \mathrm{~cm}$ bump & 0.116 & Not uncomfortable & 0 \\
\hline Multiple $5 \mathrm{~cm}$ dist. & 0.370 & A little uncomfortable & 0.5 \\
\hline Sine sweep & 0.431 & A little uncomfortable & 0.5 \\
\hline
\end{tabular}

Selection of $\rho$ algorithm considers a look-ahead estimation algorithm based on prehistoric simulations of passive suspension, which were performed to calculate FWVM and tire deformation RMS values with different road distortions and different velocities. These simulation results can be seen in Figure 5(a) and Figure 5(b). One of these results for 20 $\mathrm{km} / \mathrm{h}$ with the road classification (road category) are shown in Table III. In Figure 5(b), It is possible to see that change in tire deformation and vertical acceleration of sine sweep road distortion is quite large due to its repetitive bumps and potholes distortions, thus multiple $\rho$ can be defined for different velocities. The point where the FWVM values are lowest is when the velocity is between $20 \mathrm{~km} / \mathrm{h}$ and 40 $\mathrm{km} / \mathrm{h}$ and in the same way, in the range where the velocity

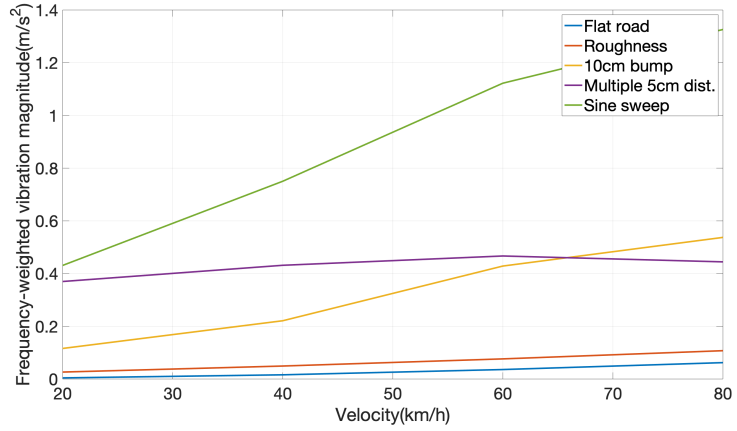

(a) FWVM values(RMS)

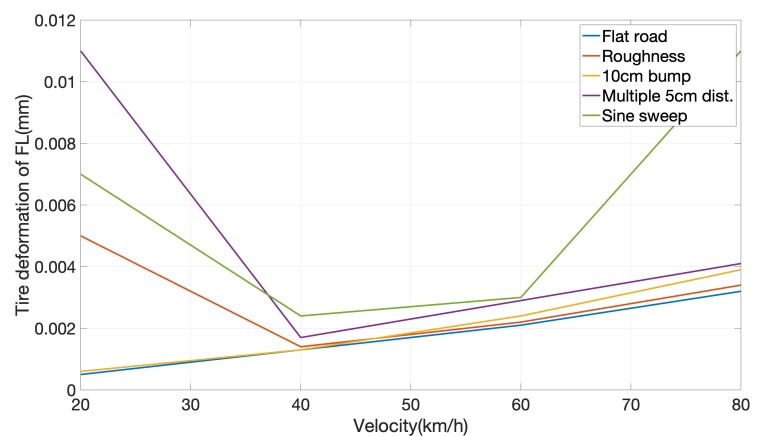

(b) Tire deformation of Front-Left wheel(RMS)

Fig. 5. Passive suspension simulation result of different road distortions

is $40-60 \mathrm{~km} / \mathrm{h}$, tire deformation is smallest. Thus, stability can be kept in consideration between $40-60 \mathrm{~km} / \mathrm{h}$ while comfort can be preferred between 20-40 $\mathrm{km} / \mathrm{h}$.

According to Table III, the FWVM value of flat road is near-zero, thus comfort-oriented semi-active suspension approach can be considered by selecting $\rho=1$ through there is not a safety-related problem. In the case of the "not uncomfortable" road category which is not near-zero, stability can be prioritized with $\rho=0$ because the RMS value of vertical acceleration is not high. If the FWVM value is between $0.315-0.63 \mathrm{~m} / \mathrm{s}^{2}$ which is defined as "a little comfortable" road category, either tire deformation and vertical acceleration are quite high, therefore both comfort and stability can be considered with the same importance by selecting $\rho=0.5$. This selected $\rho$ can be seen in Figure 9(a) and Table III.

\section{Simulation Results}

The simulation vehicle is a compact utility truck with independent front and rear suspension and half tonne of payload. A highway simulation route has been built in TruckSim environment based on real geographical and speed limit data, see Figure 6.

In order to demonstrate the effectiveness of the proposed method two different simulation has been performed and compared, one with the utility truck having conventional semi-active suspension and another with an adaptive semiactive suspension control. Note, that only a 3 kilometer section of the route has been considered, with the road 


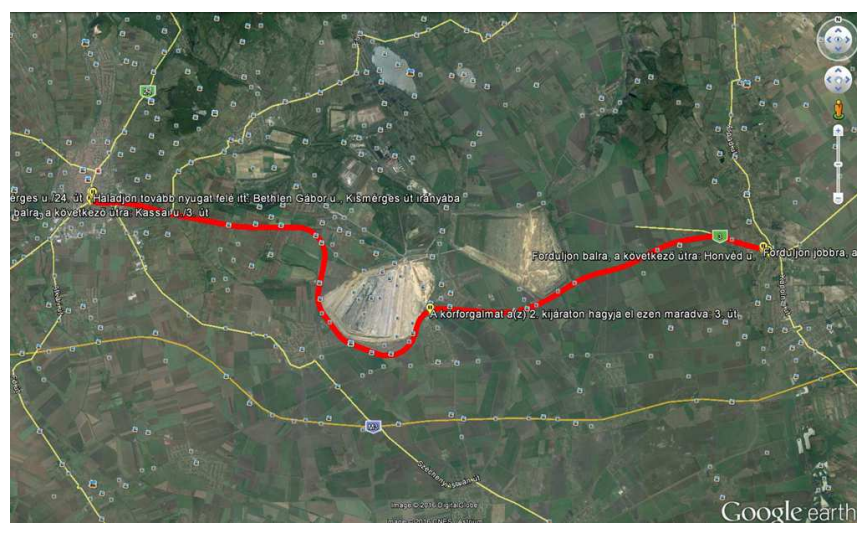

Fig. 6. Real data simulation route

geometry and roughness shown in Figure 7. As it can be observed in Figure 7(a), there are three major curves in the selected road section around $400 \mathrm{~m}, 1000 \mathrm{~m}$ and 1700 $\mathrm{m}$. Moreover, there are also three different kind of road irregularities apart from the standard road roughness, as it is shown in Figure 7(b). First, around $100 \mathrm{~m}$ there is a left and right side bump following each other having $100 \mathrm{~mm}$ of height. This kind of road irregularity represents the effect of driving over a speed bump, which is common in urban areas. Next, after $1050 \mathrm{~m}$ there are bumps and potholes following each other differently for the left to the right side of the lane, having a height and depth of $50 \mathrm{~mm}$. This road irregularity represents bad road quality with discontinuities in the asphalt. Finally, at $2000 \mathrm{~m}$ there is a longitudinal sinusoidal road irregularity with growing frequency, putting extreme stress on the suspension system of the simulated vehicle. This kind of road surface is typical at bus stops, where the frequent braking of heavy road vehicles roll up the asphalt.

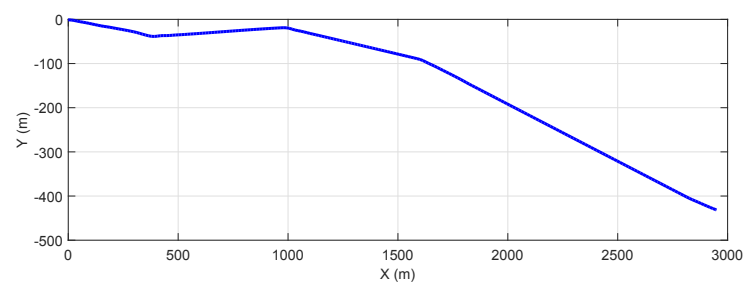

(a) Road X-Y plane

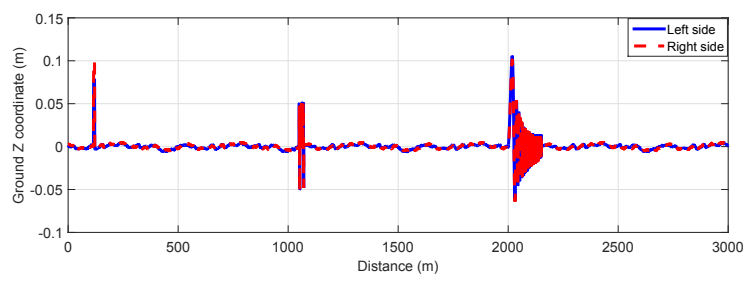

(b) Road roughness

Fig. 7. Geometry and roughness of the road section

The speed limit varies on the route, and both vehicle calculates its corresponding optimal velocity based on the energy efficient look-ahead method, see Figure 8.

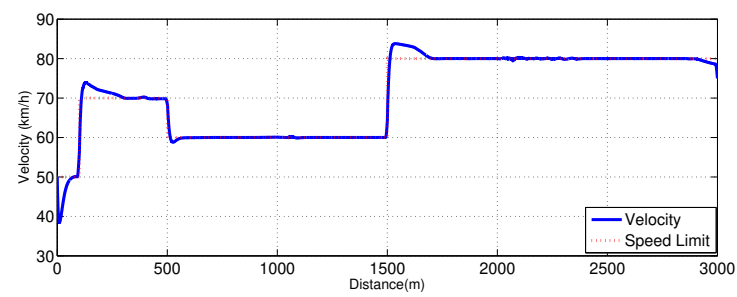

Fig. 8. Velocity of the simulated vehicles

The result of the look-ahead road consideration can be observed in Figure 9(a), where the scheduling variable $\rho$ for the LPV controller is depicted. Focusing on road irregularities (100 m, $1050 \mathrm{~m}, 2000 \mathrm{~m}$ ), the look-ahead based algorithm also selects a different value for $\rho$ based on the decision logic. The actuated control forces for each quarter suspensions are depicted in Figure 9(b), having bigger values at the three main road irregularities.

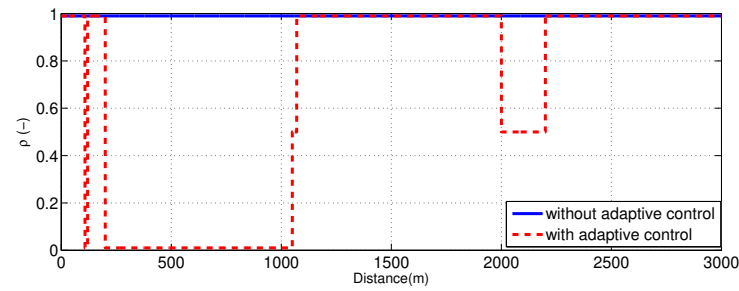

(a) Scheduling variable $\rho$

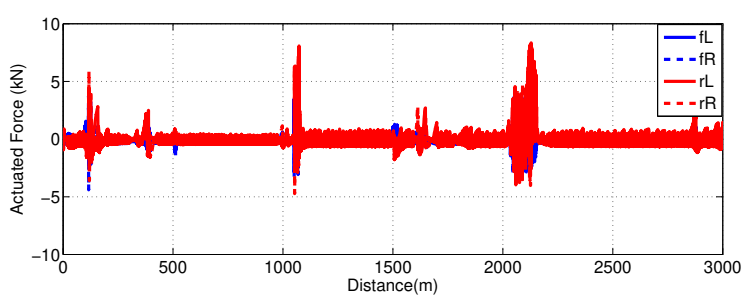

(b) Suspension control forces

Fig. 9. Scheduling variable and actuated control force

The performances defined in Section III are compared for the two simulated vehicles. It is well demonstrated by comparing Figure 10(a) and Figure 10(b), that the amount of suspension deflection over the critical bumps have been decreased for the vehicle with the proposed adaptive suspension control system.

Also, tire deformation depicted in Figure 11(a) and Figure 11(b) has been slightly decreased with the proposed method.

Thus, it has been shown that both suspension deflection and tire deformation has been improved, resulting in better stability and road holding of the vehicle, while vertical acceleration has also been improved, especially at the sinusoidal road irregularity (see Figure 12).

\section{CONCLUSION}

The paper proposed a novel integrated look-ahead semiactive suspension system, adapting the controller's perfor- 


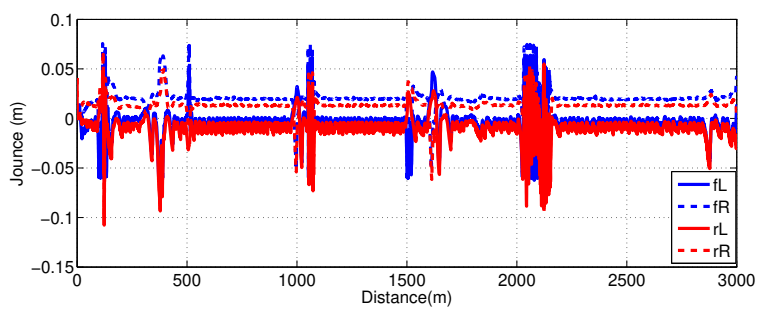

(a) Without adaptive control

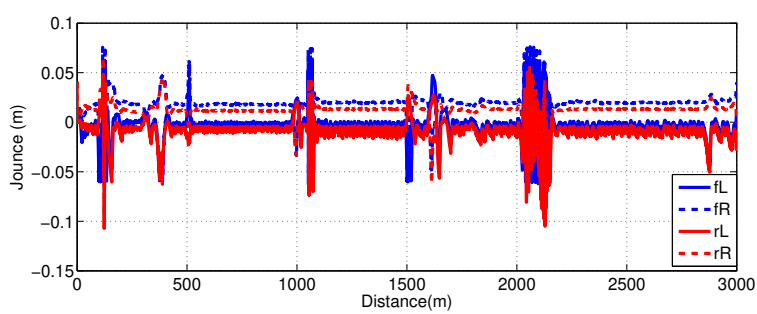

(b) With adaptive control

Fig. 10. Suspension deflection

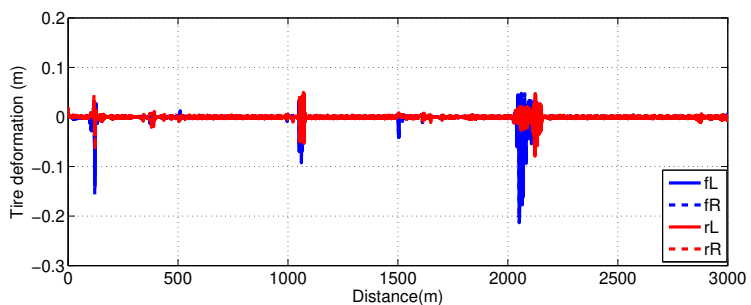

(a) Without adaptive control

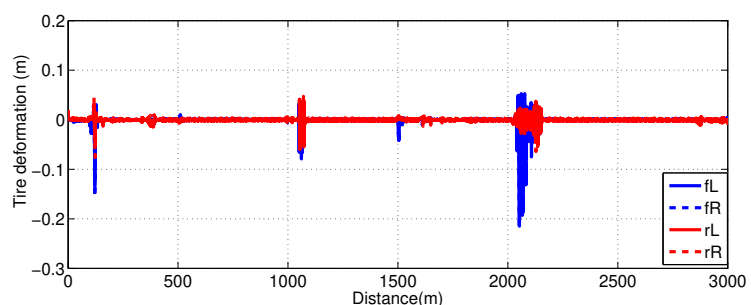

(b) With adaptive control

Fig. 11. Tire deformation

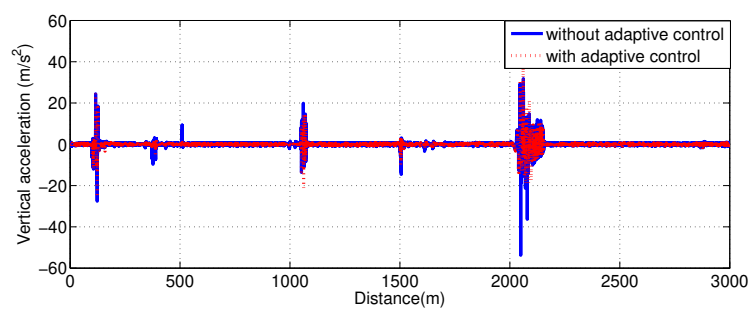

Fig. 12. Vertical acceleration

mance to further road conditions and the vehicle velocity profile given by energy-efficient cruise control. The road quality information along with the velocity reference are both considered to define the corresponding scheduling variables for the adaptive semi-active suspension system. Hence, the vehicle is able to adapt its suspension control system in coherence with oncoming road conditions and actual velocity, which improves both ride quality and stability of the vehicle. The control reconfiguration has been designed founded on the LPV framework, while the operation of the proposed method has been demonstrated in a real data simulation in the TruckSim environment.

\section{REFERENCES}

[1] W. Sun, H. Gao, and O. Kaynak, "Adaptive backstepping control for active suspension systems with hard constraints," IEEE/ASME transactions on mechatronics, vol. 18, no. 3, pp. 1072-1079, 2012.

[2] A. L. Do, O. Sename, L. Dugard, S. Aubouet, and R. A. RamirezMendoza, "An LPV Approach for Semi-Active Suspension Control," in 11th Pan-American Congress of Applied Mechanics - PACAM XI, Jan. 2010, p. PAC0546.

[3] M. Z. Chen, Y. Hu, C. Li, and G. Chen, "Semi-active suspension with semi-active inerter and semi-active damper," IFAC Proceedings Volumes, vol. 47, no. 3, pp. 11225-11230, 2014.

[4] C. Poussot-Vassal, O. Sename, L. Dugard, P. Gaspar, Z. Szabo, and J. Bokor, "A new semi-active suspension control strategy through lpv technique," Control Engineering Practice, vol. 16, no. 12, pp. 1519 1534, 2008.

[5] L. Ming, L. Yibin, R. Xuewen, Z. Shuaishuai, and Y. Yanfang, "Semiactive suspension control based on deep reinforcement learning," IEEE Access, vol. 8, pp. 9978-9986, 2020.

[6] S. M. Savaresi and C. Spelta, "Mixed Sky-Hook and ADD: Approaching the Filtering Limits of a Semi-Active Suspension," Journal of Dynamic Systems, Measurement, and Control, vol. 129, no. 4, pp. 382-392, 112006.

[7] G. Baslamisli, S Cagar and Kose, İ Emre and Anlas, "Robust control of anti-lock brake system," Vehicle System Dynamics, vol. 45, no. 3, pp. 217-232, 2007.

[8] D. Sammier, O. Sename, and L. Dugard, "Skyhook and h8 control of semi-active suspensions: some practical aspects," Vehicle System Dynamics, vol. 39, no. 4, pp. 279-308, 2003.

[9] B. de Jager, "Robust h/sub 2/optimal control of an active suspension," in Proceedings of the 1997 IEEE International Conference on Control Applications. IEEE, 1997, pp. 761-766.

[10] B. Németh and P. Gáspár, "Design of vehicle cruise control using road inclinations," International Journal of Vehicle Autonomous Systems, vol. 11, no. 4, pp. 313-333, 2013.

[11] A. Zin, O. Sename, and L. Dugard, "Switched hinf control strategy of automotive active suspensions," Proceedings of the 16th IFAC world congress (WC), Praha, Czech Republic, pp. 198-203, 2005.

[12] S. Fergani, L. Menhour, O. Sename, L. Dugard, and B. D’AndréaNovel, "A new lpv/hinf semi-active suspension control strategy with performance adaptation to roll behavior based on non linear algebraic road profile estimation," 52nd IEEE Conference on Decision and Control (CDC 2013), Florence, Italy, 2013.

[13] P. Gáspár, I. Szászi, and J. Bokor, "Active suspension design using lpv control," Proceedings of the 1st IFAC symposium on advances in automotive control (AAC), Salerno, Italy, pp. 584-589, 2004.

[14] C. Poussot-Vassal, O. Sename, L. Dugard, P. Gáspár, Z. Szabó, and J. Bokor, "A new semi-active suspension control strategy through lpv technique," Proceedings of the 1st IFAC symposium on advances in automotive control (AAC), Salerno, Italy, pp. 1519-1534, 2008.

[15] J. Bokor and G. Balas, "Linear parameter varying systems: A geometric theory and applications," 16th IFAC World Congress, Prague, 2005.

[16] A. Packard and G. Balas, "Theory and application of linear parameter varying control techniques," American Control Conference, Workshop I, Albuquerque, New Mexico, 1997.

[17] F. Wu, X. H. Yang, A. Packard, and G. Becker, "Induced $l^{2}$-norm control for LPV systems with bounded parameter variation rates," International Journal of Nonlinear and Robust Control, vol. 6, pp. 983-998, 1996.

[18] M. Elbanhawi, M. Simic, and R. Jazar, "In the passenger seat: investigating ride comfort measures in autonomous cars," IEEE Intelligent Transportation Systems Magazine, vol. 7, no. 3, pp. 4-17, 2015. 